\title{
Delay in Hand Grasp Release in Individuals with Post-stroke Hemiparesis
}

\author{
Ustinova K. I. ${ }^{1, *}$, Langenderfer J. E. ${ }^{2}$ \\ ${ }^{1}$ Department of Physical Therapy, Central Michigan University, MI, United States \\ ${ }^{2}$ School of Engineering and Technology, Central Michigan University, MI, United States
}

Copyright $\odot 2019$ by authors, all rights reserved. Authors agree that this article remains permanently open access under the terms of the Creative Commons Attribution License 4.0 International License

\begin{abstract}
This study investigated the initiation and release of hand grasp in individuals with post-stroke hemiparesis. The study included 10 individuals with mild hemiparesis and 10 age- and sex-matched control subjects. Participants were instructed to grasp and release the bottle-like handle of a manipulandum with their affected hand when prompted by auditory cues. Data points related to the initiation and release of the grasp, the maximal grip force, and the time of maximal force were analyzed with the wrist at each of five angles: flexion at $30^{\circ}$ and $60^{\circ}$, neutral at $0^{\circ}$, and extension at $30^{\circ}$ and $60^{\circ}$. The post-stroke group required more time than the control group to release the grasp. No significant differences were observed between groups for other data points. The results may suggest that the delayed grasp release remains a residual deficit even in patients with well-recovered hand function after stroke.
\end{abstract}

Keywords Reaching and Grasping, Manipulation and Release, Rehabilitation

\section{Introduction}

Grasping is a fundamental component of manipulation skills and is frequently affected by stroke [1]. Consequently, individuals with post-stroke hemiparesis experience significant declines in performance of such important activities of daily living as cooking, eating, writing, and self-hygiene. Stroke-related impairments of grasping have been intensively studied, with major emphases on the timing of grip formation and modulation of grip forces [2-4]. Much less attention has been paid, however, to post- stroke changes in grasp release [5].

Release is essential to various manipulation skills, including pushing, pulling, shaking, throwing, and transferring an object in the hand [6], and often considered interchangeably with grasping itself. This may not be the true, as those two components may be controlled and affected differently after stroke.

The purpose of the present study was to investigate the effects of unilateral stroke on grasp release and other parameters of grasp. A better understanding of impairments underlying hand manipulations may lead to the development of more efficient treatment options and, thus, an increased return to function after stroke.

\section{Materials and Methods}

\subsection{Subjects}

A convenience sample of 10 individuals with stroke (stroke group, three women) with an average (mean \pm standard deviation [SD]) age of $58.4 \pm 19.3$ years and average time since stroke of $8.1 \pm 3.9$ months participated in the study, after signing an institutionally approved consent form. The control group comprised 10 healthy height-, sex-, and age-matched individuals (age: 60. $3 \pm$ 19.8 years, six women).

All participants with stroke had arm and hand motor impairments, with the following clinical test scores: 46-56 points (51.8 \pm 10.8 points) on the Motor Arm and Hand section of the Fugl-Meyer Assessment Scale [7]; 18-24 points $(23.3 \pm 2.0$ points $)$ on the Sensory Section of the Fugl-Meyer Assessment Scale; and 0-3 points (1.2 \pm 1.1 points) on the modified Ashworth scale [8].

\subsection{Experimental Procedure}

A custom-made manipulandum device (Fig. 1) was used to measure grip strength with two $445-\mathrm{N}$ force transducers, placed on either side (fingers and thumb) of a bottle-shaped handle. The handle was attached to a rotating platform that could be locked into different angles between $90^{\circ}$ of wrist flexion and extension (Fig. 1). The manipulandum has been validated in previous experiments [9]. During a single experimental session, a participant sat in a chair with the involved extremity placed comfortably on the arm rest at approximately $90^{\circ}$ of shoulder flexion, with hand and 
fingers around the manipulandum handle.

Each participant performed three 8-s trials of grasping the handle, placed consecutively in five wrist positions: extension of $60^{\circ}\left(\right.$ Ext60), extension of $30^{\circ}$ (Ext30), neutral at $0^{\circ}$ (Neutral), flexion at $30^{\circ}(\mathrm{Fl} 330)$, and flexion at $60^{\circ}$

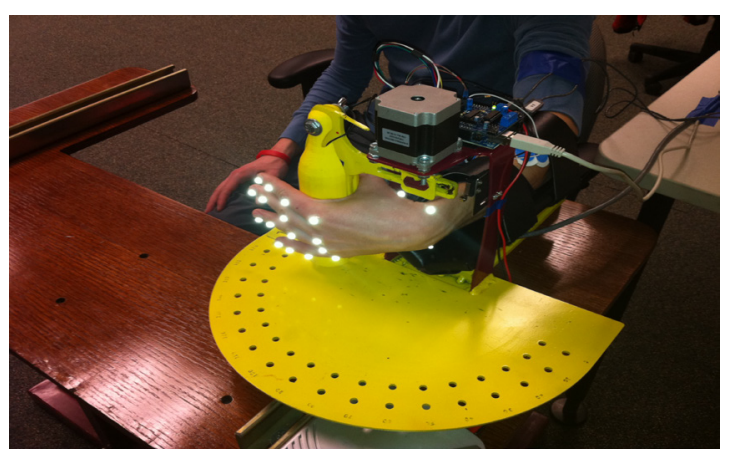

(Flx60). During each trial, the participant was prompted to grasp the handle with maximal force as quickly as possible after the first auditory cue (Go, Fig. 2A), and then to release the handle as quickly as possible after the second auditory cue (Stop).

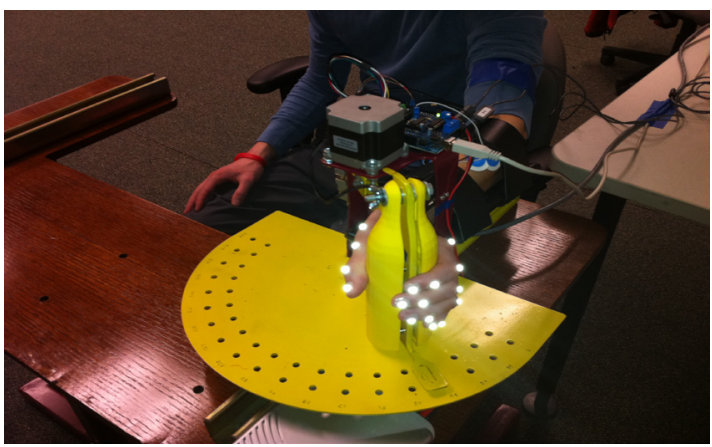

Figure 1. Manipulandum device with hand placed in the flexed and extended positions.

A
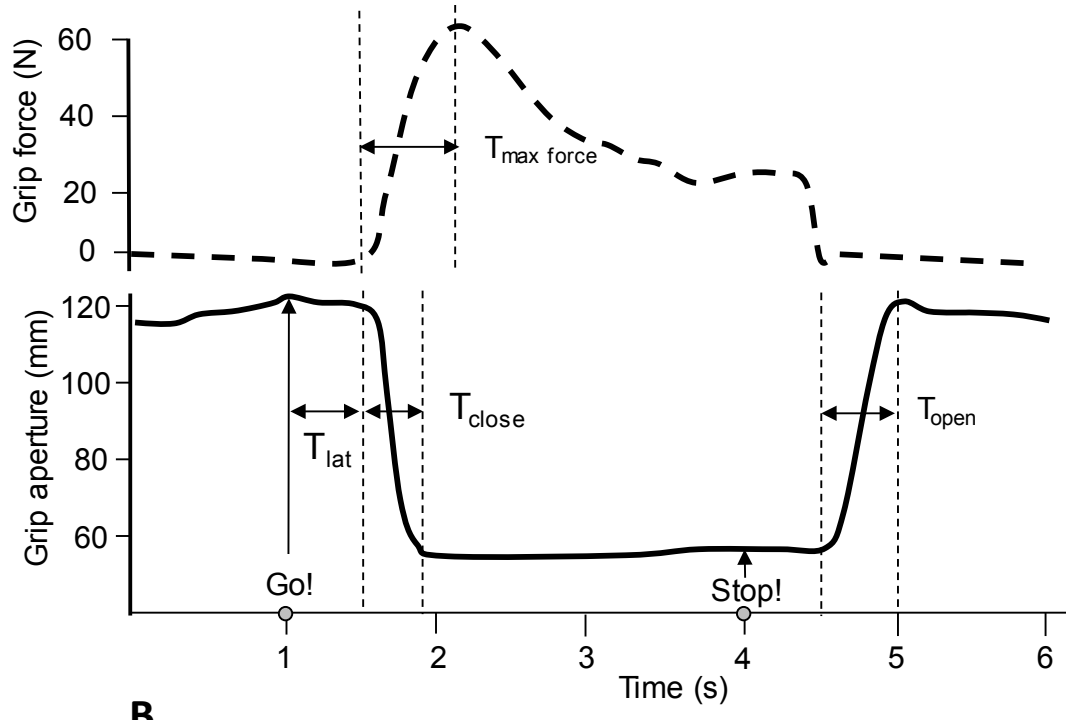

B

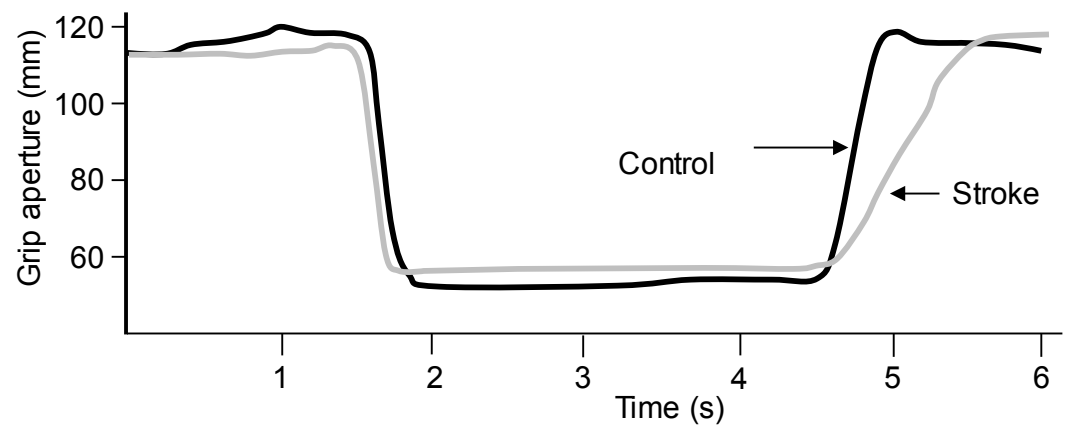

Figure 2. (A) Trajectories of grip aperture (solid) and grip force (dashed) with indicators of the following events and phases: Go - first auditory cue; Stop - second auditory cue; $T_{\text {lat }}$ - latency of grasp initiation; $T_{\text {close }}-$ time of grasp; $T_{\text {open }}-$ time for grip aperture to return to baseline; $F_{\max }-$ maximal force elicited by fingers; and $\mathrm{T}_{\max }$ force - time of maximal force. (B) Trajectories of grip aperture in one participant with stroke (gray) and one control participant (black). 


\subsection{Data Analysis}

Grip aperture was defined as the distance between two reflective markers, placed on the distal phalanx of the first and second digits, as captured by a Vicon T160 system at $100 \mathrm{~Hz}$. From trajectories of grip aperture (Fig. 2A, solid line) and grip force (dashed line), several outcome measures were calculated: a) latency of grasp initiation $\left(T_{\text {lat }}\right)$, calculated as the time between the signal Go and the time that the grip aperture decreased by $>2 \mathrm{SD}$ of the baseline; $b$ ) time of grasp $\left(\mathrm{T}_{\text {close }}\right)$, calculated as the time between $T_{\text {lat }}$ and the time that grip aperture reached a minimal stable value; c) time of grasp release $\left(T_{\text {open }}\right)$, calculated as the time that the grip aperture returned to baseline; $d)$ maximal force elicited by fingers $\left(\mathrm{F}_{\max }\right)$; and $\left.\mathrm{e}\right)$ time of maximal force $\left(\mathrm{T}_{\max \text { force }}\right)$.

Each outcome measure was averaged across three trials for each of the five wrist positions and for each subject. Averaged means were compared between groups with the Mann-Whitney U test for each of the five wrist positions, and within groups by Friedman's Analysis of Variance (ANOVA) with the significance level set at 0.01 .

\section{Results}

Figure 2B illustrates trajectories of grip aperture for two representative participants: one control (black line) and one individual with stroke (gray line). Both participants initiated grasp quickly (for $<0.5 \mathrm{~s}$ ) and held the handle for almost $3 \mathrm{~s}$ (as required). However, there was a marked difference between participants in their release of the grasp. Release took approximately $0.4 \mathrm{~s}$ for the control participant, compared to about $0.7 \mathrm{~s}$ for the participant with stroke.

Table 1 presents statistical measures (means, medians, and low-high quartiles) for each outcome measure and results of statistical tests. Significant between-group differences were found only in one variable (Topen) for four out five wrist positions (Ext30: $U=19, p=0.011$, Neutral: $U=19.5, p=0.013$; Flx30: $U=22, p=0.017$; and Flx60: $U=23, p=0.015$ ).

Table 1. Mean (median) [low:high quartile] of outcome measures in stroke and control groups.

\begin{tabular}{|c|c|c|c|c|c|c|}
\hline \multirow{2}{*}{$\begin{array}{c}\text { Wrist } \\
\text { position }\end{array}$} & Ext60 & Ext30 & Neutral & Flx30 & Flx60 & \multirow{2}{*}{$\begin{array}{c}\text { Friedman's } \\
\text { ANOVA }\end{array}$} \\
\hline & \multicolumn{5}{|c|}{$\mathrm{T}_{\text {lat }}(\mathrm{s})$} & \\
\hline Stroke & $\begin{array}{l}0.44(0.41) \\
{[0.36: 0.50]}\end{array}$ & $\begin{array}{l}0.52(0.45) \\
{[0.31: 0.73]}\end{array}$ & $\begin{array}{l}0.54(0.46) \\
{[0.42: 0.67]}\end{array}$ & $\begin{array}{l}0.49(0.45) \\
{[0.36: 0.55]}\end{array}$ & $\begin{array}{l}0.41(0.41) \\
{[0.36: 0.48]}\end{array}$ & $\begin{array}{c}\mathrm{x}^{2}(4)=2.08 \\
\mathrm{p}=.71\end{array}$ \\
\hline Healthy & $\begin{array}{l}0.65(0.53) \\
{[0.47: 0.83]}\end{array}$ & $\begin{array}{l}0.62(0.59) \\
{[0.50: 0.70]}\end{array}$ & $\begin{array}{l}0.55(0.59) \\
{[0.44: 0.66]}\end{array}$ & $\begin{array}{l}0.50(0.53) \\
{[0.39: 0.64]}\end{array}$ & $\begin{array}{l}0.52(0.46) \\
{[0.44: 0.50]}\end{array}$ & $\begin{array}{c}\mathrm{x}^{2}(4)=8.70 \\
\mathrm{p}=.07\end{array}$ \\
\hline $\begin{array}{c}\text { Mann- } \\
\text { Whitney U }\end{array}$ & $\mathrm{U}=12, \mathrm{p}=.04$ & $\mathrm{U}=33, \mathrm{p}=.34$ & $U=39, p=.65$ & $\mathrm{U}=41, \mathrm{p}=.75$ & $\mathrm{U}=21.5, \mathrm{p}=.06$ & \\
\hline \multicolumn{7}{|c|}{$\mathrm{T}_{\text {open }}(\mathrm{s})$} \\
\hline Stroke & $\begin{array}{l}0.58(0.57) \\
{[0.41: 0.65]}\end{array}$ & $\begin{array}{l}0.74(0.58) \\
{[0.49: 0.92]}\end{array}$ & $\begin{array}{l}0.75(0.62) \\
{[0.43: 0.90]}\end{array}$ & $\begin{array}{l}0.72(0.58) \\
{[0.44: 0.79]}\end{array}$ & $\begin{array}{l}0.74(0.65) \\
{[0.43: 0.90]}\end{array}$ & $\begin{array}{c}\mathrm{x}^{2}(4)=0.37 \\
\mathrm{p}=.98\end{array}$ \\
\hline Healthy & $\begin{array}{l}0.42(0.36) \\
{[0.31: 0.55]}\end{array}$ & $\begin{array}{l}0.42(0.40) \\
{[0.32: 0.47]}\end{array}$ & $\begin{array}{l}0.40(0.41) \\
{[0.32: 0.47]}\end{array}$ & $\begin{array}{l}0.42(0.38) \\
{[0.32: 0.54]}\end{array}$ & $\begin{array}{l}0.45(0.44) \\
{[0.36: 0.48]}\end{array}$ & $\begin{array}{c}\mathrm{x}^{2}(4)=3.43 \\
\mathrm{p}=.48\end{array}$ \\
\hline $\begin{array}{c}\text { Mann- } \\
\text { Whitney U }\end{array}$ & $\mathrm{U}=18, \mathrm{p}=.05$ & $\mathrm{U}=19, \mathrm{p}=.01 \%$ & $\mathrm{U}=19.5, \mathrm{p}=.01$ * & $\mathrm{U}=22, \mathrm{p}=.01 \%$ & $\mathrm{U}=23, \mathrm{p}=\mathbf{0 . 0 1}$ * & \\
\hline \multicolumn{7}{|c|}{$\mathrm{T}_{\text {close }}(\mathrm{s})$} \\
\hline Stroke & $\begin{array}{l}0.45(0.41) \\
{[0.33: 0.53]}\end{array}$ & $\begin{array}{l}0.42(0.43) \\
{[0.26: 0.54]}\end{array}$ & $\begin{array}{l}0.59(0.52) \\
{[0.37: 0.87]}\end{array}$ & $\begin{array}{l}0.53(0.51) \\
{[0.39: 0.59)}\end{array}$ & $\begin{array}{l}0.53(0.50) \\
{[0.41: 0.65]}\end{array}$ & $\begin{array}{c}\mathrm{x}^{2}(4)=7.40 \\
\mathrm{p}=.11\end{array}$ \\
\hline Healthy & $\begin{array}{l}0.41(0.38) \\
{[0.33: 0.43]}\end{array}$ & $\begin{array}{l}0.41(0.40) \\
{[0.33: 0.50]}\end{array}$ & $\begin{array}{l}0.38(0.35) \\
{[0.25: 0.47]}\end{array}$ & $\begin{array}{l}0.39(0.42) \\
{[0.25: 0.42]}\end{array}$ & $\begin{array}{l}0.42(0.40) \\
{[0.29: 0.51]}\end{array}$ & $\begin{array}{c}\mathrm{x}^{2}(4)=1.06 \\
\mathrm{p}=.89\end{array}$ \\
\hline $\begin{array}{c}\text { Mann- } \\
\text { Whitney U }\end{array}$ & $\mathrm{U}=28, \mathrm{p}=.50$ & $\mathrm{U}=47, \mathrm{p}=.85$ & $\mathrm{U}=26, \mathrm{p}=.07$ & $\mathrm{U}=31, \mathrm{p}=.16$ & $\mathrm{U}=31, \mathrm{p}=.14$ & \\
\hline \multicolumn{7}{|c|}{$\mathrm{T}_{\max \text { force }}(\mathrm{s})$} \\
\hline Stroke & $\begin{array}{l}1.37(1.18) \\
{[0.84: 1.87]}\end{array}$ & $\begin{array}{l}1.46(1.28) \\
{[0.93: 2.12]}\end{array}$ & $\begin{array}{l}1.62(1.83) \\
{[0.82: 1.96]}\end{array}$ & $\begin{array}{l}1.76(1.74) \\
{[1.51: 2.29]}\end{array}$ & $\begin{array}{l}1.56(1.55) \\
{[1.17: 1.98]}\end{array}$ & $\begin{array}{c}\mathrm{x}^{2}(4)=7.50 \\
\mathrm{p}=.11\end{array}$ \\
\hline Healthy & $\begin{array}{l}1.74(1.59) \\
{[1.27: 2.15]}\end{array}$ & $\begin{array}{l}1.57(1.54) \\
{[1.18: 1.91]}\end{array}$ & $\begin{array}{l}1.62(1.58) \\
{[1.13: 2.08]}\end{array}$ & $\begin{array}{l}1.51(1.57) \\
{[1.05: 1.78]}\end{array}$ & $\begin{array}{l}1.40(1.16) \\
{[1.06: 1.69]}\end{array}$ & $\begin{array}{c}\mathrm{x}^{2}(4)=4.70 \\
\mathrm{p}=.31\end{array}$ \\
\hline $\begin{array}{c}\text { Mann- } \\
\text { Whitney U }\end{array}$ & $\mathrm{U}=19, \mathrm{p}=.18$ & $\mathrm{U}=40, \mathrm{p}=.71$ & $\mathrm{U}=43, \mathrm{p}=.90$ & $\mathrm{U}=41, \mathrm{p}=.77$ & $\mathrm{U}=31, \mathrm{p}=.27$ & \\
\hline \multicolumn{7}{|c|}{$F_{\max }(\mathrm{N})$} \\
\hline Stroke & $\begin{array}{l}25.3(19.5) \\
{[6.11: 36.2]}\end{array}$ & $\begin{array}{l}27.8(22.3) \\
{[13.9: 27.8]}\end{array}$ & $\begin{array}{l}25.1(22.0) \\
{[11.2: 30.6]}\end{array}$ & $\begin{array}{l}39.1(36.2) \\
{[27.9: 50.2]}\end{array}$ & $\begin{array}{l}41.8(27.8) \\
{[25.0: 47.3]}\end{array}$ & $\begin{array}{c}x^{2}(4)=11.0 \\
p=.02 *\end{array}$ \\
\hline Healthy & $\begin{array}{l}25.0(22.3) \\
{[8.57: 39.0]}\end{array}$ & $\begin{array}{l}30.6(19.5) \\
{[11.1: 33.4]}\end{array}$ & $\begin{array}{l}50.2(38.9) \\
{[14.0: 64.1]}\end{array}$ & $\begin{array}{l}52.9(47.3) \\
{[16.7: 69.6]}\end{array}$ & $\begin{array}{l}55.7(33.4) \\
{[18.9: 86.3]}\end{array}$ & $\begin{array}{c}\mathrm{x}^{2}(4)=10.2 \\
\mathrm{p}=.03 *\end{array}$ \\
\hline $\begin{array}{c}\text { Mann-- } \\
\text { Whitney U }\end{array}$ & $\mathrm{U}=23, \mathrm{p}=.94$ & $\mathrm{U}=34, \mathrm{p}=.88$ & $\mathrm{U}=23, \mathrm{p}=.22$ & $\mathrm{U}=31, \mathrm{p}=.66$ & $\mathrm{U}=32, \mathrm{p}=.73$ & \\
\hline
\end{tabular}

Significant differences are indicated by bold font and (*) 
Within-group differences, have been found in both groups, but mainly for the maximal force: $\mathrm{F}_{\max }=$ $\left(\mathrm{x}^{2}(4)=10.2, \mathrm{p}=0.037\right)$ in the stroke group, and $\mathrm{F}_{\max }=$ $\left(x^{2}(4)=11.0, p=0.025\right)$ in the control group. In both groups, greater force was applied to the manipulandum handle at the Flx30 and Flx60 wrist positions.

\section{Discussion}

The stroke group differed from the control group in only one experimental parameter, as it took significantly longer to release the grasp. The time to initiate and complete the grasp, the maximal grip force, and the time to achieve maximal force were similar in both groups. No stroke participant had a limited range of motion or significantly impaired strength of the wrist or hand/digit extensor muscles. These observations may suggest that the grasp release remains a residual deficit even in patients with relatively intact ability to form hand grasp.

Several reasons could explain why people with stroke may experience greater difficulties with releasing hand grip than with grasping objects. First, successful recovery of hand functions is traditionally evaluated by testing hand flexor strength and grasp-forming ability [10], whereas few rehabilitation protocols and tests exist for grading the recovery of hand extensors and grasp release. Thus, less attention is paid to recovery of grasp release. Second, recovery of hand/digit extension may occur slowly after stroke, and muscle extensors retain greater weakness than muscle flexors for a longer recovery period. This process is not only due to a reduced ability to activate motoneurons of the hand extensors [4], but also due to the increased resting tone of flexor muscles [11]. Third, with the resultant lack of functionality after stroke, the person decreases their use of the affected arm and hand, thereby losing strength in extensor muscles, which, on a daily basis, are utilized less intensively than the flexor muscles. These factors can possibly explain why grasp release can still be delayed even in people with relatively mild impairments of hand function after stroke.

\section{Acknowledgements}

Research project was sponsored by National Science Foundation Major Research Initiative grant of USA CBET-1337511

\section{REFERENCES}

[1] Raghavan P. The nature of hand motor impairment after stroke and its treatment. Curr Treat Options Cardivasc Med, 9, 221-228, 2007
[2] Michaelson SM, Magdalon EC, Levin MF. Grip aperture scaling to object size in chronic stroke. Motor Control, 32, 197-217, 2009

[3] Naik SK, Patten C, Lodha N, Coombes SA, Cauraugh JH. Force control deficits in chronic stroke: grip formation and release phases. Exp Brain Res, 211, 1-15, 2011

[4] Lang CE, Wagner JM, Bastian AJ, Hu Q, Edwards DF, Sahrmann SA, Dromerick AW. Deficits in grasp versus reach during acute hemiparesis. Exp Brain Res, 166, 126136,2005

[5] Seo NJ, Rymer WZ, Kamper DG. Delays in grip initiation and termination in persons with stroke: effects of arm support and active muscle stretch exercise. J Neurophysiol, 101, 3108-3115, 2009

[6] Jeannerod M. The formation of finger grip during prehension: a cortically mediated visuomotor pattern. Brain Res, 9, 99-116, 1986.

[7] Fugl-Meyer AR, Jääsko L, Leyman L, Olsson S, Steglind S. The post-stroke hemiparetic patient. I. A method for evaluation of physical performance. Scand J Rehab Med, 7, 13-31, 1975

[8] Bohannon RW, Smith MB. Inter rater reliability of a modified Ashworth Scale of muscle spasticity. Phys Ther 67, 206-207, 1987

[9] Sherd KR, Duthie MH, Langenderfer JE. Development of a wrist manipulandum for assessment of motor control and biomechanics. American Society of Engineering Education, $1-7,2014$

[10] Trombly CA, Thayer-Nason L, Bliss G, Girard CA, Lyrist LA, Brexa-Hooson A. The effectiveness of therapy in improving finger extension in stroke patients. Am J Occup Ther, 40, 612-617, 1986

[11] Kamper DG, Harvey RL, Suresh S, Rymer WZ. Relative contributions of neural mechanisms versus muscle mechanics in promoting finger extension deficits following stroke. Muscle Nerve, 28, 309-318, 2003 